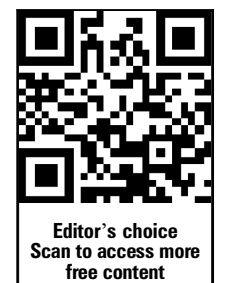

For numbered affiliations see end of article.

\section{Correspondence to} Dr Maria P Bambo, Ophthalmology Department, Miguel Servet University Hospital, C/Padre Arrupe, Consultas Externas de Oftalmologia, Zaragoza 50009, Spain; mpbamborubio@gmail. com

Received 3 July 2013 Revised 29 August 2013 Accepted 6 September 2013 Published Online First 30 September 2013
To cite: Bambo MP, GarciaMartin E, Perez-Olivan $S$, et al. Br J Ophthalmol 2013;97:1543-1548.

\title{
Diagnostic ability of a new method for measuring haemoglobin levels in the optic nerve head in multiple sclerosis patients
}

\author{
Maria Pilar Bambo, ${ }^{1,2}$ Elena Garcia-Martin, ${ }^{1,2}$ Susana Perez-Olivan, ${ }^{1,2}$ Jose Sigut, ${ }^{3}$ \\ Francisco Fumero, ${ }^{3}$ Juan Luis Fuentes, ${ }^{1,2}$ Jose R Ara, ${ }^{4}$ Jesus Martin, ${ }^{4}$ \\ Jose M Larrosa, ${ }^{1,2}$ Manuel Gonzalez-De la Rosa ${ }^{5}$
}

\begin{abstract}
Aims To evaluate a new method for measuring haemoglobin $(\mathrm{Hb})$ levels and quantifying the colour changes in the optic nerve head of multiple sclerosis (MS) patients to detect axonal loss and consequently optic disc atrophy.
\end{abstract}

Material and methods $40 \mathrm{MS}$ patients and 40 age and sex-matched healthy subjects were included in this prospective cross-sectional study and underwent a full ophthalmological examination, including three photographs of the optic disc. The Laguna ONhE ('optic nerve hemoglobin'; Insoft SL, Tenerife, Spain) software was used to obtain the $\mathrm{Hb}$ analysis in each of the 24 sectors and average $\mathrm{Hb}$ of optic disc photographs acquired. Reproducibility of measurements provided by Laguna ONhE program was analysed.

Results MS patients showed significant reduction of optic disc $\mathrm{Hb}$ percentages in average $\mathrm{Hb}(58.99 \%$ in MS, $65.39 \%$ in healthy subjects; $p<0.001)$ and in almost all analysed sectors with the largest differences in temporal sectors. Laguna ONhE program showed good reproducibility measuring $\mathrm{Hb}$ percentages in MS patients and healthy subjects.

Conclusions Measurements of optic disc Hb levels obtained with Laguna ONhE software had good ability detecting optic atrophy and axonal loss in MS patients. This method had good reliability and is easy to implement in routine clinical practice.

\section{INTRODUCTION}

Axonal loss is detected in multiple sclerosis (MS) patients and is the main cause of disability in this neurodegenerative disease. Several studies report a correlation between axonal loss in the optic nerve of MS patients and the extent of functional disability ${ }^{1-3}$ and the affectation in their quality of life. ${ }^{4}$ Axonal loss can be observed in the optic nerve as a progressive pallor by fundus examination with an ophthalmoscope. However, the human eye cannot quantify axonal loss or detect it early (only when more than $50 \%$ of nerve fibres are lost, papillary atrophy can be observed).

'Laguna ONhE' (optic nerve head hemoglobin) is a new method designed by a group of ophthalmologists and engineers which allows measuring the amount of haemoglobin $(\mathrm{Hb})$ at the optic nerve head $(\mathrm{ONH})$ using conventional fundus colour photographs that compensates for different variables such as illumination or lens absorption and diffusion. Laguna ONhE has already been used for early diagnosis of glaucomatous optic neuropathy demonstrating high precision and reproducibility compared with classic functional and structural tests used in glaucoma,${ }^{5}$ but this new technology has not been previously used to analyse neuro-ophthalmological patients.

Unlike other regions of the posterior pole of the eye, the $\mathrm{ONH}$ contains a significant amount of just one pigment, $\mathrm{Hb}$, which is responsible for this particular colour. Therefore, measuring the amount of $\mathrm{Hb}$ in different sectors of $\mathrm{ONH}$ is actually quantifying the colour changes which occur in the disc as a result of different processes, such as MS.

Blood perfusion in $\mathrm{ONH}$ has been measured previously and several studies have measured blood volume using reflectometry, ${ }^{6-8}$ but these authors have not described objective and reproducible methods to measure the amount of $\mathrm{Hb}$ at the ONH. However, the Laguna ONhE program (Insoft SL, Tenerife, Spain) provides reproducible and objective measurements, is cheap and easy to perform, and it may be applicable in future clinical practice in ophthalmology.

Loss of ganglion cells can be detected by means of ocular imaging technologies such as optical coherence tomography (OCT). Given the value of retinal nerve fibre layer (RNFL) examination as a method of evaluation and diagnosis in MS, ${ }^{9} 10$ the aim of this study was to investigate the ability of Laguna ONhE program detecting early axonal loss in MS patients. To the best of our knowledge, there are no studies that analyse the Laguna ONhE ability to detect changes in $\mathrm{Hb}$ amount in different sectors of the papilla (and therefore papillary colour changes) in patients with MS compared with healthy subjects. Our study also assessed the reproducibility of Laguna ONhE measurements in healthy and MS subjects.

\section{MATERIALS AND METHODS}

The design of the study followed the Declaration of Helsinki Principles and the study protocol was approved by the Clinical Research Ethics Committee of Aragon (Zaragoza, Spain), and informed written consent was obtained from all participants.

\section{Subjects and measurement protocol}

Required inclusion criteria were as follows: bestcorrected visual acuity of $20 / 40$ or better, refractive error within \pm 5.00 dioptres equivalent sphere and \pm 2.00 dioptres astigmatism, and transparent ocular 
media (nuclear colour/opalescence, cortical or posterior subcapsular lens opacity <1), according to the Lens Opacities Classification System III system. ${ }^{11}$ Exclusion criteria included previous intraocular surgery, diabetes or other diseases affecting the visual field or neurological system, and current use of medications that could affect visual function.

From June 2012 to February 2013, two independent samples of 40 consecutive healthy individuals and 40 MS patients who attended our service referred by neurologists for their annual eye examination were prospectively recruited from one ophthalmologist under the area of influence of our hospital. The diagnosis of MS was based on standard clinical and neuroimaging criteria. $^{12}$ Related medical records were carefully reviewed, including disease duration, the expanded disability status scale, disease-modifying treatments, acute MS attacks and the presence of prior episodes of optic neuritis (ON). Subjects referred for refraction who underwent routine examination without abnormal ocular findings were recruited as normal eye controls.

Two MS patients did not complete all of the required tests and were therefore excluded from further analysis. A total of 78 eyes (38 eyes of MS patients and 40 eyes of healthy subjects) of white European origin were included in the statistical analysis. One eye from each subject was randomly chosen for the study, unless only one eye met the inclusion criteria. Twelve eyes of the MS patients group (30\%) presented at least one episode of ON.

All participants underwent a full ophthalmological examination, including clinical history, visual acuity, biomicroscopy of the anterior segment using a slit lamp, Goldmann applanation tonometry and ophthalmoscopy of the posterior segment.

Three photographs of the optic disc were obtained using a Canon CF 60 DSi retinograph (Canon Incorporation, Tokio, Japan) connected to a Canon EOS 1DS Mark III body camera (Canon Incorporation). The Laguna ONhE program analysed three spectral components of ONH photographs: blue, green and red. The $\mathrm{ONH}$ areas with high $\mathrm{Hb}$ content mainly reflect red light. In contrast, areas with a low $\mathrm{Hb}$ component reflect a lower proportion of the red component compared with the green and blue light. Using different concentrations or different thicknesses of various red blood cell dilutions, it may be established experimentally that the photographic images obtained with this technique can be used to determine the amount of $\mathrm{Hb}{ }^{5}$

The Laguna ONhE software used mathematical algorithms for automatic component segmentation to perform a semiautomatic delimitation of the $\mathrm{ONH}$ border and to identify the central retinal vessels. Thus, two areas of the $\mathrm{ONH}$ were defined: the central retinal vessels and the $\mathrm{ONH}$ tissue itself. The result obtained for the vessels was used as the reference value for calculating the $\mathrm{Hb}$ content in the tissue. The image of the papilla was divided automatically into eight $45^{\circ}$ radial sectors, and two concentric rings also were defined using $1 / 3$ and $2 / 3$ of disc radius, obtaining average $\mathrm{Hb}$ and 24 sectors as shown in figure 1 . Finally, the influence of the lens status was compensated for by analysing the differences between the green and blue components before calculating the results of the $\mathrm{Hb}$ amount. The blue, green and red components were assessed with an image analysis program with the Matlab image processing toolbox (The MathWorks, Incorporation, Natick, Massachusetts, USA).

\section{Statistical analysis}

All statistical analyses were calculated using SPSS (V.20.0; SPSS Incorporation, Chicago, Illinois, USA) and MedCalc (V.9.6.4.0; MedCalc Software, Mariakerke, Belgium) statistical software.

The Kolmogorov-Smirnov test was used to assess sample distribution. $\mathrm{Hb}$ percentage in each of the 24 sectors and the average $\mathrm{Hb}$ were compared between patients and healthy controls by means of a Student $t$ test given their normal distribution. Values of $p<0.05$ were considered to be indicative of statistically significant differences. We then compared the percentages of $\mathrm{Hb}$ in each of 24 sectors and the mean $\mathrm{Hb}$ between MS patients with previous ON $(n=12)$ and MS patients without a history of $\mathrm{ON}(n=26)$ by Mann-Whitney U test. Values of $\mathrm{p}<0.05$ were considered to indicate statistically significant differences. We also calculated the Pearson correlation coefficient between LogMAR visual acuity and the percentage of $\mathrm{Hb}$ in each of the 24 sectors of the papilla (including mean $\mathrm{Hb}$ ).
Figure 1 The image of the papilla was divided automatically by Laguna ONhE (optic nerve head hemoglobin) device into eight $45^{\circ}$ radial sectors, and two concentric rings using $1 / 3$ and $2 / 3$ of the disc radius. Laguna $\mathrm{ONhE}$ program analysed the amount of haemoglobin in each of these 24 sectors and the average haemoglobin.

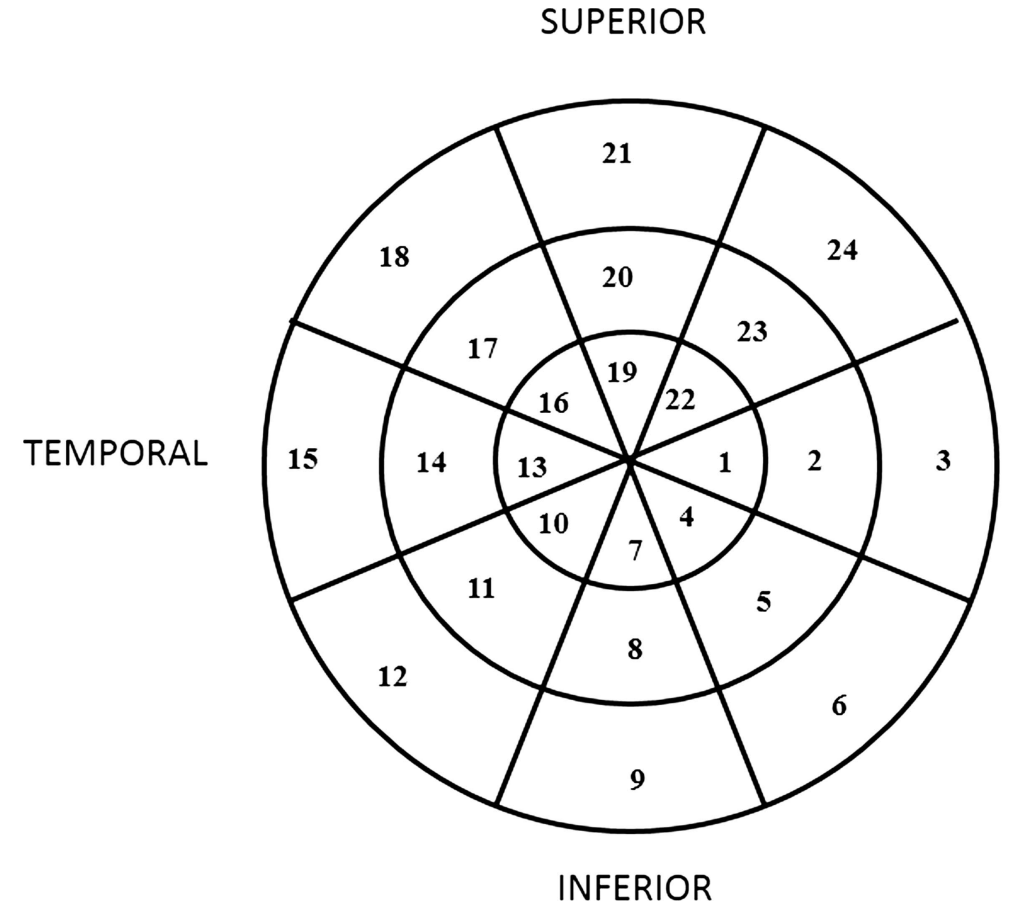

NASAL 
Table 1 Epidemiological and disease characteristics of patients with MS and healthy subjects

\begin{tabular}{lcll}
\hline & $\begin{array}{l}\text { MS patients } \\
\text { (n 38) }\end{array}$ & $\begin{array}{l}\text { Healthy } \\
\text { subjects (n 40) }\end{array}$ & p Value* \\
\hline Age (years) (mean (SD)) & $49.65(12.23)$ & $47.96(10.63)$ & 0.514 \\
Women:men (\% women) & $23: 15(60.53 \%)$ & $26: 14(65 \%)$ & 0.800 \\
BCVA (Snellen scale) (mean (SD)) & $0.87(0.04)$ & $0.98(0.02)$ & 0.002 \\
Intraocular pressure & $13.98(4.50)$ & $14.34(2.44)$ & 0.332 \\
$\begin{array}{l}\text { Disease duration (years) } \\
\text { (mean (SD)) }\end{array}$ & $7.33(1.91)$ & - & - \\
$\begin{array}{l}\text { EDSS score (mean (range)) } \\
\text { Eyes with optic neuritis history }\end{array}$ & $2.49(0-6.5)$ & - & - \\
(n (\%)) & $12(31.6 \%)$ & - & - \\
\hline
\end{tabular}

*Significant difference $(p<0.05)$ between normal and MS groups for each population. BCVA, best corrected visual acuity; EDSS, expanded disability status scale;

MS, multiple sclerosis; $n$, number.

For each parameter, the coefficient of variation (COV) was calculated as the SD divided by the average of the measurement value and expressed as a percentage. Most authors consider that methods with a COV less than $10 \%$ have high reproducibility, while a COV less than $5 \%$ indicates very high reproducibility. ${ }^{13}$ To assess the reliability of the repeated measurements, the intraclass correlation coefficients for absolute agreement was calculated. They measure the concordance for continuous variables and correct correlations for systematic bias. The intraclass

Table 2 Mean and SD in parenthesis of haemoglobin's percentage analysing optic disc photographs with Laguna ONhE program (optic nerve head hemoglobin) of MS patients and healthy subjects, and statistical significance ( $p)$

\begin{tabular}{|c|c|c|c|}
\hline & MS patients & Healthy subjects & p Value* \\
\hline Average $\mathrm{Hb}$ & $58.99(11.53)$ & $65.39(10.63)$ & $<0.001$ \\
\hline $\mathrm{Hb} 1$ & $69.76(17.24)$ & 71.96 (16.09) & 0.383 \\
\hline $\mathrm{Hb} 2$ & $68.14(15.40)$ & 72.1 (14.78) & 0.082 \\
\hline $\mathrm{Hb} 3$ & $61.97(12.12)$ & $67.07(12.24)$ & 0.005 \\
\hline $\mathrm{Hb} 4$ & $67.23(16.70)$ & $69.09(15.37)$ & 0.445 \\
\hline $\mathrm{Hb} 5$ & 68.55 (14.32) & 72.89 (13.77) & 0.041 \\
\hline $\mathrm{Hb} 6$ & $62.04(12.34)$ & $66.34(12.22)$ & 0.019 \\
\hline $\mathrm{Hb} 7$ & $59.32(17.70)$ & $63.12(16.06)$ & 0.140 \\
\hline $\mathrm{Hb} 8$ & $62.76(14.19)$ & $69.7(11.30)$ & 0.001 \\
\hline $\mathrm{Hb} 9$ & $62.3(11.82)$ & $67.8(11.48)$ & 0.002 \\
\hline $\mathrm{Hb} 10$ & $49.4(19.38)$ & $56.67(17.87)$ & 0.011 \\
\hline $\mathrm{Hb} 11$ & 50.24 (16.95) & $57.51(15.45)$ & 0.004 \\
\hline $\mathrm{Hb} 12$ & $51.89(13.15)$ & $59.45(12.73)$ & $<0.001$ \\
\hline $\mathrm{Hb} 13$ & 47.17 (21.19) & $55.28(17.75)$ & 0.008 \\
\hline $\mathrm{Hb} 14$ & $46.31(17.32)$ & $53.75(16.02)$ & 0.004 \\
\hline $\mathrm{Hb} 15$ & 47.33 (13.72) & $56.5(14.26)$ & $<0.001$ \\
\hline $\mathrm{Hb} 16$ & $53.2(21.74)$ & $59.77(18.22)$ & 0.035 \\
\hline Hb 17 & $55.46(17.34)$ & $63.44(15.17)$ & 0.002 \\
\hline $\mathrm{Hb} 18$ & $57.27(13.00)$ & $65.15(13.36)$ & $<0.001$ \\
\hline $\mathrm{Hb} 19$ & $63.17(22.23)$ & $66.57(16.53)$ & 0.277 \\
\hline $\mathrm{Hb} 20$ & $68.88(15.30)$ & 75.97 (13.31) & 0.001 \\
\hline $\mathrm{Hb} 21$ & $69.04(12.01)$ & $74.36(11.81)$ & 0.003 \\
\hline $\mathrm{Hb} 22$ & $70.81(19.92)$ & $71.76(16.27)$ & 0.737 \\
\hline $\mathrm{Hb} 23$ & $74.17(15.25)$ & 78.95 (13.51) & 0.031 \\
\hline $\mathrm{Hb} 24$ & $69.11(12.07)$ & $74.03(12.14)$ & 0.007 \\
\hline
\end{tabular}

Bold values correspond to statistically significant $p$ values $(p<0.05)$.

*Significant difference $(p<0.05)$ in T-Student test between healthy subjects and MS patients.

$\mathrm{Hb}$, haemoglobin; MS, multiple sclerosis. correlation coefficients interpretation that we used was slight reliability (for values between 0 and 0.2 ), fair reliability (for values between 0.21 and 0.4 ), moderate reliability (for values between 0.41 and 0.6 ), substantial reliability (for values between 0.61 and 0.8 ) and almost perfect reliability (for values of intraclass correlation coefficients higher than 0.81$).^{14}$

\section{RESULTS}

A total of 38 eyes from relapsing-remitting MS patients and 40 eyes from healthy subjects were examined. A previous acute $\mathrm{ON}$ attack was reported for 12 eyes (31.6\%), while 26 eyes (68.4\%) were studied from patients with no history of ON. The duration of the MS ranged from 9 months to 28 years with a median of 7.33 years since diagnosis. No differences were observed between MS patients and the healthy groups in age and sex. Epidemiological and disease characteristics of patients with MS and healthy subjects are shown in table 1 .

All $\mathrm{Hb}$ percentages were lowest in MS patients than in healthy controls and we found significant differences in average $\mathrm{Hb}$ and in all sectors except in 1, 2, 4, 7, 19 and 22 (T-Student, $\mathrm{p}<0.005)$. The main differences were found in temporal sectors of the papilla $(12,13,14,15,17$ and 18), oscillating between $7.44 \%$ (in sector 14) and $9.17 \%$ of difference (in sector 15) (table 2).

Comparison between $\mathrm{Hb}$ percentages in MS patients with previous $\mathrm{ON}$ and MS patients without previous ON by MannWhitney $U$ test showed statistically significant differences in the

Table 3 Mean and SD in parenthesis of Hb's percentage analysing optic disc photographs with Laguna ONhE (optic nerve hemoglobin) program of MS patients with previous ON attack and without history of previous attack, and statistical significance $(p)$

\begin{tabular}{|c|c|c|c|}
\hline & $\begin{array}{l}\text { MS patients without } \\
\text { ON }(n=26)\end{array}$ & $\begin{array}{l}\text { MS patients with } \\
\text { ON }(n=12)\end{array}$ & p Value* \\
\hline Average $\mathrm{Hb}$ & $59.67(10.11)$ & $56.55(11.26)$ & 0.013 \\
\hline $\mathrm{Hb} 1$ & 69.88 (15.98) & $69.56(17.09)$ & 0.205 \\
\hline $\mathrm{Hb} 2$ & $68.24(14.66)$ & $68.02(15.32)$ & 0.025 \\
\hline $\mathrm{Hb} 3$ & $63.09(12.01)$ & $60.23(12.89)$ & 0.027 \\
\hline $\mathrm{Hb} 4$ & $67.23(15.77)$ & $67.04(16.66)$ & 0.321 \\
\hline $\mathrm{Hb} 5$ & $69.40(13.01)$ & 67.99 (13.89) & 0.112 \\
\hline $\mathrm{Hb} 6$ & $62.94(12.21)$ & $60.51(13.50)$ & 0.066 \\
\hline $\mathrm{Hb} 7$ & 59.62 (15.98) & $59.01(16.54)$ & 0.135 \\
\hline $\mathrm{Hb} 8$ & $64.10(14.10)$ & $60.22(15.01)$ & 0.014 \\
\hline $\mathrm{Hb} 9$ & $63.45(10.55)$ & $61.41(12.28)$ & 0.035 \\
\hline $\mathrm{Hb} 10$ & 51.59 (18.88) & 48.11 (19.71) & 0.030 \\
\hline Hb 11 & $52.65(16.32)$ & $48.89(16.66)$ & 0.004 \\
\hline $\mathrm{Hb} 12$ & $54.02(13.56)$ & 49.00 (13.99) & 0.005 \\
\hline $\mathrm{Hb} 13$ & 47.99 (19.67) & 45.89 (21.79) & 0.026 \\
\hline $\mathrm{Hb} 14$ & $47.18(17.00)$ & $45.87(18.29)$ & $<0.001$ \\
\hline Hb 15 & $48.33(12.98)$ & $46.75(13.82)$ & 0.003 \\
\hline Hb 16 & $53.72(20.19)$ & $52.95(21.83)$ & 0.043 \\
\hline Hb 17 & 56.77 (17.56) & $54.86(17.02)$ & 0.005 \\
\hline Hb 18 & $59.06(13.45)$ & $56.11(13.94)$ & 0.004 \\
\hline Hb 19 & $63.77(21.87)$ & $62.67(23.01)$ & 0.087 \\
\hline $\mathrm{Hb} 20$ & 69.59 (15.19) & $67.28(15.98)$ & 0.021 \\
\hline $\mathrm{Hb} 21$ & $69.97(14.08)$ & $67.70(12.89)$ & 0.024 \\
\hline $\mathrm{Hb} 22$ & $71.88(18.23)$ & 70.00 (19.99) & 0.225 \\
\hline $\mathrm{Hb} 23$ & $74.83(15.76)$ & $73.61(15.05)$ & 0.056 \\
\hline $\mathrm{Hb} 24$ & 70.05 (12.01) & $68.95(12.32)$ & 0.012 \\
\hline
\end{tabular}

${ }^{*}$ Significant difference $(p<0.05)$ in Mann-Whitney $U$ test between MS without ON and MS patients with $\mathrm{ON}$.

$\mathrm{Hb}$, haemoglobin; MS, multiple sclerosis; ON, optic neuritis. 
mean $\mathrm{Hb}$ amount in 16 sectors (table 3), demonstrating that $\mathrm{ON}$ attacks reduce the amount of $\mathrm{Hb}$ in the papilla of MS patients compared with patients without previous ON. Again, the main differences in the percentages of $\mathrm{Hb}$ were found in the temporal sectors (10-18) of the optic disc.

Figure 2 shows, as an example, the morphology of the papilla and the corresponding pseudo-images indicating the $\mathrm{Hb}$ levels provided by Laguna ONhE analysis in a healthy control and a patient with MS.

The correlations between the LogMAR visual acuity and the percentage of $\mathrm{Hb}$ in the different sectors were statistically significant, although very slight ( $\mathrm{r}$ range between -0.047 and $-0.299)$.

Laguna ONhE program showed good COV and intraclass correlation coefficients in MS patients (range 5.05\%-12.77\% in COV, $0.795-0.979$ in intraclass correlation coefficient) and healthy subjects (range 3.02\%-10.22\% in COV, 0.898-0.989 in intraclass correlation coefficient). The average $\mathrm{Hb}$ value was the parameter with the lowest variability in both groups (COV of $5.05 \%$ and $3.02 \%$ in MS patients and healthy controls, respectively, and intraclass correlation coefficient of 0.974 and 0.98 , respectively). We found that the measurement variability was higher in patients with fixation or ocular movement alterations, even when the quality of the photograph was good. All parameters showed less variability in healthy eyes, as shown in table 4 .

\section{DISCUSSION}

The $\mathrm{ONH}$ contains a significant amount of $\mathrm{Hb}$ pigment and its colour essentially depends on it. Systems for fundus imaging measure the amount of light reflected at different wavelengths. For example, a detector that captures three images, one centred on spectral component blue, another on green and another on red, reveals that in areas with high $\mathrm{Hb}$ content, most of the light reflected is red, less is green and even less is blue. In contrast, in areas with a low $\mathrm{Hb}$ content, green and blue light is largely reflected. Some tissue regions, which may have good perfusion such as the neuroretinal rim, reflect more green and blue than the central retinal vessels because they have less $\mathrm{Hb}$. Thus, in areas with atrophy or poorly vascularised tissue, the proportion of reflected green and blue increases and is perceived in the image as whitening. This fact justifies not obtain significant differences between MS group and control group in $\mathrm{Hb}$ levels of the central sectors of the papilla, as are those corresponding to the physiological cup.

To obtain absolute and reproducible results for the $\mathrm{ONH}$, a reference pattern is needed to compensate lens absorption and diffusion as well as change in the intensity and spectral composition of the light used for illumination. If this is not corrected, for example, in patients with cataracts, the relative redness of the image may lead to an overestimation of $\mathrm{Hb}$ content in the tissue. Laguna ONhE program obtained the reference value from the central retinal vessels on their way through the $\mathrm{ONH}$.

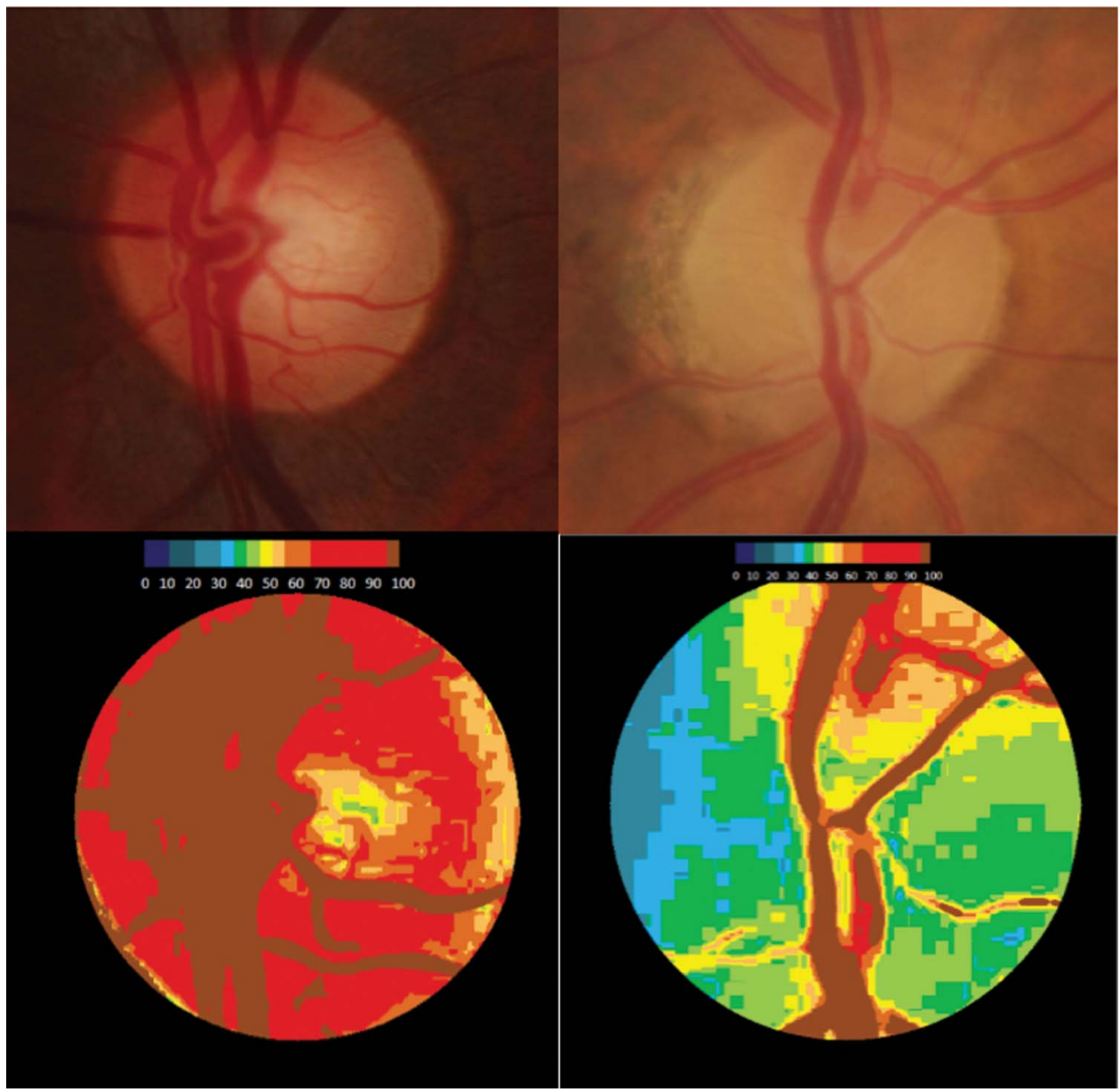

Figure 2 Examples of image of the papilla in a healthy subject (left column) and in a patient with multiple sclerosis (right column). Upper images show the colour fundus photographs of the optic discs, and lower images show the corresponding pseudo-images representing the amount of haemoglobin. A colorimetric scale is shown at the top of the lower images to assess the amount of haemoglobin. 
Table 4 COV and intraclass correlation coefficient for repeated $\mathrm{Hb}$ percentages provided by Laguna ONhE (optic nerve head hemoglobin) device

\begin{tabular}{|c|c|c|c|c|}
\hline & \multicolumn{2}{|c|}{$\begin{array}{l}\text { Multiple sclerosis } \\
\text { eyes }\end{array}$} & \multicolumn{2}{|c|}{ Healthy eyes } \\
\hline & cov & ICC & COV & ICC \\
\hline Average $\mathrm{Hb}$ & 5.05 & 0.974 & 3.02 & 0.989 \\
\hline $\mathrm{Hb} 1$ & 9.84 & 0.896 & 7.77 & 0.945 \\
\hline $\mathrm{Hb} 2$ & 8.96 & 0.795 & 6.95 & 0.898 \\
\hline $\mathrm{Hb} 3$ & 7.01 & 0.903 & 5.03 & 0.946 \\
\hline $\mathrm{Hb} 4$ & 10.89 & 0.894 & 5.22 & 0.943 \\
\hline $\mathrm{Hb} 5$ & 8.12 & 0.822 & 6.99 & 0.931 \\
\hline $\mathrm{Hb} 6$ & 7.07 & 0.916 & 4.03 & 0.954 \\
\hline $\mathrm{Hb} 7$ & 9.05 & 0.973 & 3.36 & 0.972 \\
\hline $\mathrm{Hb} 8$ & 6.29 & 0.972 & 4.02 & 0.987 \\
\hline $\mathrm{Hb} 9$ & 6.29 & 0.953 & 4.00 & 0.966 \\
\hline $\mathrm{Hb} 10$ & 12.26 & 0.941 & 9.92 & 0.965 \\
\hline $\mathrm{Hb} 11$ & 10.25 & 0.885 & 7.76 & 0.953 \\
\hline $\mathrm{Hb} 12$ & 7.17 & 0.947 & 5.21 & 0.977 \\
\hline $\mathrm{Hb} 13$ & 12.77 & 0.949 & 10.22 & 0.969 \\
\hline $\mathrm{Hb} 14$ & 11.11 & 0.857 & 9.86 & 0.980 \\
\hline $\mathrm{Hb} 15$ & 8.15 & 0.937 & 5.59 & 0.959 \\
\hline $\mathrm{Hb} 16$ & 12.16 & 0.950 & 9.66 & 0.976 \\
\hline $\mathrm{Hb} 17$ & 9.96 & 0.863 & 8.56 & 0.903 \\
\hline Hb 18 & 7.07 & 0.935 & 4.89 & 0.973 \\
\hline Hb 19 & 9.41 & 0.979 & 7.74 & 0.988 \\
\hline $\mathrm{Hb} 20$ & 6.75 & 0.971 & 4.96 & 0.988 \\
\hline $\mathrm{Hb} 21$ & 5.79 & 0.950 & 3.36 & 0.975 \\
\hline $\mathrm{Hb} 22$ & 9.43 & 0.923 & 7.45 & 0.966 \\
\hline $\mathrm{Hb} 23$ & 7.55 & 0.863 & 6.69 & 0.943 \\
\hline $\mathrm{Hb} 24$ & 5.72 & 0.920 & 3.26 & 0.954 \\
\hline
\end{tabular}

$\mathrm{Hb}$ may be measured at each point or sector of the papilla using the same formula $(\mathrm{F})$ to define the chromatic characteristics of the tissue (FT) and the reference vessels (FV). The amount of $\mathrm{Hb}$ at each point of the tissue is expressed as: $(\mathrm{FT} / \mathrm{FV}) \times 100 .^{15}$

The aim of our study was to evaluate whether optic disc photographs analysis using Laguna ONhE program is a good diagnostic marker for axonal damage in MS, by quantifying the amount of $\mathrm{Hb}$ in different sectors of the $\mathrm{ONH}$. The calculation of the percentage of $\mathrm{Hb}$ is an indirect way to measure the colour of the papilla and thus to identify the areas with axonal loss or atrophy earlier and with more accuracy than fundus routine examination.

Numerous studies have demonstrated RNFL thinning in eyes with a previous episode of $\mathrm{ON}$ and in patients with MS who have never had an acute clinical episode of ON using OCT devices, ${ }^{16}{ }^{17}$ and it has been suggested that RNFL thickness measurement provided by digital image analysis techniques may be useful as a surrogate marker of brain atrophy in MS. ${ }^{18} 19$ However, these technologies (such as OCT) are not available in all clinical centres. The method used in this study may be applied in all clinical centres because only a good photograph of optic nerve is necessary for image processing with Laguna ONhE software.

Based on other studies, the time required for measurements made with digital image analysis techniques to record retrograde degeneration after an inflammatory episode in the optic nerve is 6 months. $^{20} 21$ In the present study, patients with ON in the 6 months preceding the study were excluded, so all subjects were considered to have stable MS. The changes registered in optic nerve of MS patients in our study were caused only by MS-related chronic neurodegeneration, not by acute heavy axonal loss that occurs in acute relapsing $\mathrm{ON}$ episodes.

We found that $\mathrm{Hb}$ amount in each one of the 24 sectors of the papilla obtained by Laguna ONhE analysis was higher in healthy subjects than in MS patients, especially in temporal sector. A greater loss of nerve fibres in the temporal sector of papilla has been observed in neurodegenerative diseases such as MS with digital image analysis techniques. ${ }^{22}$ We also found that the amount of $\mathrm{Hb}$ is reduced in patients who have had previous ON compared with those who have not, but further studies with a larger sample size are needed to confirm this result. We found no correlation between the amount of $\mathrm{Hb}$ in the optic disc and the visual acuity of the subjects.

The Laguna ONhE program is also being used in the study of glaucoma with promising results compared with other structural and functional tests used to monitor glaucoma progression, as González de la Rosa et $a l^{5}$ recently demonstrated. The present study, based on the findings of Gonzalez de la Rosa et al, evaluates the clinical application of this software to evaluate other optical neuropathies caused by neurodegenerative diseases such as MS, in which the optic nerve digital imaging analysis had demonstrated its utility to detect axonal loss and correlation with functional status of these patients. ${ }^{1-4}$ Laguna ONhE seems to be useful in other pathologies or researches, for example, in patients with sleep apnoea ${ }^{23} 24$ and other optic neuropathies with perfusion anomalies or optic disc atrophy.

The analysis of the $\mathrm{Hb}$ content in $\mathrm{ONH}$ photographs using Laguna ONhE provided useful and reproducible information about the change in colour of the papilla secondary to RNFL loss. This method detects the paleness due to optic atrophy and it can quantify it. Nevertheless, the high variability of normal human optic disc morphology (different disc sizes and distribution of the RNFL bundles in the ONH), as well as refractive errors, poor fixation and eye movements, may affect measurement accuracy. Clinicians should take into account this limitation when using this method, as well as other digital image analysis technologies.

Longer studies with larger samples are needed to assess the ability of Laguna ONhE program as a new biomarker of neurodegeneration in MS. Our findings suggest an important clinical application but they should be confirmed and extended for other ophthalmological diseases causing axonal loss in the optic disc.

\section{Author affiliations}

${ }^{1}$ Ophthalmology Department, Miguel Servet University Hospital, Zaragoza, Spain ${ }^{2}$ Aragones Institute of Health Sciences, Zaragoza, Spain

${ }^{3}$ Systems Engineering Department, University of La Laguna, La Laguna, Spain

${ }^{4}$ Neurology Department, Miguel Servet University Hospital, Zaragoza, Spain

${ }^{5}$ Ophthalmology Department, University of La Laguna, La Laguna, Spain

Funding Supported in part by the Instituto de Salud Carlos III grant PI0990617 and PI12/02301M

Competing interests MG-DIR has a proprietary interest in the Laguna ONhE program.

\section{Patient consent Obtained.}

Ethics approval Clinical Research Ethics Committee of Aragon (Zaragoza, Spain). Provenance and peer review Not commissioned; externally peer reviewed.

\section{REFERENCES}

1 Fisher JB, Jacobs DA, Markowitz CE, et al. Relation of visual function to retinal nerve fiber layer thickness in multiple sclerosis. Ophthalmology 2006;113:324-32.

2 Gordon-Lipkin E, Chodkowski B, Reich DS, et al. Retinal nerve fiber layer is associated with brain atrophy in multiple sclerosis. Neurology 2007;69:1603-9. 
3 Garcia-Martin E, Pueyo V, Pinilla I, et al. Fourier-domain OCT in multiple sclerosis patients: reproducibility and ability to detect retinal nerve fiber layer atrophy. Invest Ophthalmol Vis Sci 2011:52:4124-31.

4 Garcia-Martin E, Rodriguez-Mena D, Herrero R, et al. Neuro-ophthalmologic evaluation, quality of life and functional disability in MS patients. Neurology 2013:81:76-83.

5 González de la Rosa M, González-Hernández M, Sigut J, et al. Measuring hemoglobin levels in the Optic Nerve Head: comparisons with other structural and functional parameters of glaucoma. Invest Ophtalmol Vis Sci 2013;1:482-8.

6 Delori FC. Reflectometry measurements of the optic disc blood volume. In: Lambrou GN, Greve EL. eds. Ocular blood flow in glaucoma. Means, methods and measurements. Berkeley, CA: Kugler and Ghedini, 1989:155-63.

7 Sebag J, Feke GT, Delori FC, et al. Anterior optic nerve blood flow in experimental optic atrophy. Invest Ophthalmol Vis Sci 1985;26:1415-22.

8 Crittin M, Riva CE. Functional imaging of the human papilla and peripapillary region based on flicker-induced reflectance changes. Neurosci Lett 2004;360:141-44.

9 Garcia-Martin E, Pueyo V, Martin J, et al. Progressive changes in the retinal nerve fiber layer in patients with multiple sclerosis. Eur J Ophthalmol 2010;20:167-73.

10 Garcia-Martin E, Pablo LE, Herrero R, et al. Diagnostic ability of a linear discriminant function for spectral-domain optical coherence tomography in patients with multiple sclerosis. Ophthalmology 2012;119:1705-11.

11 Chylack LT Jr, Wolfe JK, Singer DM, et al. Longitudinal Study of Cataract Study Group. The lens opacities classification system III. Arch Ophthalmol 1993;111:831-6.

12 Polman CH, Reingold SC, Banwell B, et al. Diagnostic criteria for multiple sclerosis: 2010 revisions to the McDonald criteria. Ann Neurol 2011:69:292-302.

13 Hirasawa $\mathrm{H}$, Araie M, Tomidokoro A, et al. Reproducibility of thickness measurements of macular inner retinal layers using SD-OCT with or without correction of ocular rotation. Invest Ophthalmol Vis Sci 2013;54:2562-70.
14 Sim DA, Keane PA, Mehta $\mathrm{H}$, et al. Repeatability and reproducibility of choroidal vessel layer measurements in diabetic retinopathy using enhanced depth optical coherence tomography. Invest Ophthalmol Vis Sci 2013;54:2893-901.

15 Dill DB, Costill DL. Calculation of percentage changes in volumes of blood, plasma, and red cells in dehydration. J App/ Physiol 1974;37:247-48.

16 Pueyo V, Martin J, Fernandez J, et al. Axonal loss in the retinal nerve fiber layer in patients with multiple sclerosis. Mult Scler 2008;14:609-14.

17 Parikh RS, Parikh SR, Sekhar GC, et al. Normal age-related decay of retinal nerve fiber layer thickness. Ophthalmology 2007;114:921-26.

18 Frohman EM, Dwyer MG, Frohman T, et al. Relationship of optic nerve and brain conventional and non-conventional MRI measures and retinal nerve fiber layer thickness, as assessed by OCT and GDx: a pilot study. J Neurol SC 2009;282:96-105.

19 Petzold A, de Boer JF, Schippling S, et al. Optical coherence tomography in multiple sclerosis: a systematic review and meta-analysis. Lancet Neurol 2010;9:921-32.

20 Costello F, Coupland S, Hodge W. Quantifying axonal loss after optic neuritis with optical coherence tomography. Ann Neurol 2006;59:963-69.

21 Noval S, Contreras I, Rebolleda G, et al. Optical coherence tomography versus automated perimetry for follow-up of optic neuritis. Acta Ophthalmol Scand 2006;84:790-94

22 Garcia-Martin E, Pueyo V, Almarcegui C, et al. Risk factors for progressive axonal degeneration of the retinal nerve fibre layer in multiple sclerosis patients. $\mathrm{Br} \mathrm{J}$ Ophthalmol 2011;95:1577-82.

23 Mojon DS, Hess CW, Goldblum D, et al. Primary open-angle glaucoma is associated with sleep apnea syndrome. Ophthalmologica 2000;214:115-18.

24 Roberts TV, Hodge C, Graham SL, et al. Prevalence of nocturnal oxygen desaturation and self-reported sleep-disordered breathing in glaucoma. J Glaucoma 2009;18:114-18. 